\title{
CELLULAR RESPONSES TO FREE GRAFTING OF THE EXTENSOR DIGITORUM LONGUS MUSCLE OF THE RAT
}

\author{
FAY M. HANSEN-SMITH* and BRUCE M. CARLSON**
}

Department of Anatomy, 4622 Medical Sciences II, University of Michigan, Ann Arbor, MI 48109 (U.S.A.)

(Received 8 August, 1978)

(Accepted 1 December, 1978)

\section{SUMMARY}

The cellular and subcellular responses related to the survival or destruction and subsequent regeneration of muscle fibers within the freely grafted extensor digitorum longus muscle of the rat were examined by light and electron microscopy. A small number of fibers at the periphery of the grafts survived the initial ischemia but underwent denervation changes and accumulated lipid deposits. The majority of fibers in the grafts, however, became ischemic and underwent an intrinsic degeneration within 4 hours. Cellmediated destruction of the degenerating fibers occurred as the grafts became revascularized. The basal laminae and some of the satellite cells were the only elements of the original fibers that persisted. Regeneration began at the periphery of the graft within three days after grafting and reached the center about three days later. After phagocytosis of the original fibers, presumptive myoblasts within the grafts differentiated into myoblasts and myotubes. The formation of myotubes followed a biphasic pattern of development comparable to that of normal fetal muscle. Although most of the myotubes were formed within the basal lamina remaining from the original fiber, there was also evidence for regeneration outside the basal lamina. Myotubes matured into muscle fibers which were essentially normal in appearance when examined up to 180 days after grafting. Some fibers, however, were atrophic, presumably due to a failure to become innervated, and some fibers were joined by myo-myous junctions. Pre-denervated grafts and Marcaine-treated grafts were also examined. There were more surviving fibers in pre-denervated grafts, and cellmediated destruction of degenerating fibers proceeded more rapidly than in normal

This work was supported by grants from the Muscular Dystrophy Associations, Inc. and NIH (NS-13116).

* Present address: University of Detroit, School of Dentistry, 2985 East Jefferson Avenue, Detroit, MI 48207, U.S.A.

** Correspondence and reprint requests to: Bruce M. Carlson, Department of Anatomy, University of Michigan, Ann Arbor, MI 48109, U.S.A. 
grafts. No surviving fibers were found in Marcaine-treated grafts. The changes in these grafts were otherwise similar to normal grafts. A schematic model of the spatial and temporal sequence of degeneration and regeneration within a free muscle graft is presented.

\section{INTRODUCTION}

During recent years the free grafting of entire mammalian muscles has come into increasing use both in the research laboratory (Carlson 1978) and in selected clinical situations (Thompson 1974). The morphological basis underlying the successful establishment of a free muscle graft is the degeneration and subsequent regeneration of most of the muscle fibers within the graft. Analysis of both the degenerative and regenerative responses in a muscle graft is complicated by the fact that during the early days after transplantation there is a gradient of developmental events within a single graft (Carlson and Gutmann 1975a). The most peripheral part of the graft is occupied by a thin rim of original muscle fibers that apparently survive the grafting procedure. Within the rim of surviving fibers, all the remaining fibers are in a state of ischemic necrosis. Ultimately, these muscle fibers undergo a cell-mediated fragmentation, followed by regeneration of new muscle fibers within the basal laminae of the original, non-fragmented muscle fibers. Fragmentation begins peripherally and proceeds toward the center of the graft in step with the ingrowth of the vascular network that invades the graft from all sides. The regeneration of new muscle fibers follows the fragmentation of old ones. Consequently, the earliest formed, and most mature, regenerating muscle fibers are peripheral, and the most recent, and least mature, are in the center of the graft.

Because of the clinical implications of the free grafting model, there is a particular need for information on the survival, degeneration and regeneration of muscle fibers in a muscle graft (Mastaglia et al. 1975; Schiaffino et al. 1975; Lischka et al. 1977; Schmalbruch 1977). In the laboratory setting the extensor digitorum longus muscle of the rat has been subject to a number of transplantation studies, but ultrastructural aspects of the freely grafted extensor digitorum longus have so far received only scant attention. Changes within the graft are sufficiently complex in terms of the variety and arrangement of degenerative and regenerative events that it is important to study the cellular reactions in the context of the muscle as a tissue or an organ. The objective of this study was to analyze with respect to spatial and temporal relationships the cellular and subcellular events that occur in the freely grafted extensor digitorum longus muscle in the rat, for the purpose of correlating details of muscle fiber survival, degeneration, regeneration and maturation with previous histological (Carlson and Gutmann 1975a), biochemical (Wagner et al. 1977), histochemical (Magon et al., in preparation) and physiological (Carlson and Gutmann 1975b) studies on the same system. 


\section{METHODS}

Male Sprague-Dawley rats (175-200 g) from Charles River Farms were used for this study. The extensor digitorum longus of one leg was freely grafted, as reported previously (Carlson and Gutmann 1975a). The muscle was completely excised, including its neurovascular bundle, and was then grafted back into the original bed. It was sutured to the tendons of origin and insertion, but no vascular or neural connections were made. The animals were anesthetized by ether during the grafting procedure and at the time of removal of the muscles for analysis. Both the grafted muscle and the contralateral control muscle were removed after 4 or $8 \mathrm{hr}$, or 1-8, 10 , $15,20,30,60,120$ or 150 days. Sample blocks for electron microscopy were taken from the middle third of the muscle and fixed overnight in $2 \%$ cacodylate-buffered gluteraldehyde $(\mathrm{pH} 7.38)$. In half the animals examined after 20 or more days, both the grafts and the contralateral control muscles were fixed by perfusion via the abdominal aorta. Fixation of early grafts by perfusion is unsatisfactory because of the avascular condition of much of the center of the graft. The tissues were post-fixed in $1 \%$ cacodylate-buffered osmium tetroxide, dehydrated in ethanol, and embedded in Spurr resin. Survey sections $(1 \mu \mathrm{m})$ were stained with toluidine blue or according to the method of Humphrey and Pittman (1974). Gold or silver sections for electron microscopy were examined with a Hitachi HU-11A electron microscope. A total of 44 normal grafts were examined.

In the second experimental series the hind limb was denervated by severing the sciatic nerve 14 days before the extensor digitorum longus muscle was grafted (Carlson and Gutmann 1975a). In the third experimental series the removed muscle was injected with $0.75 \%$ Marcaine (Winthrop) and then immersed in Marcaine solution for 10 min before being grafted back into its original bed (Carlson and Gutmann 1976). The animals in the second and third series were killed 1, 4, 10 or 30 days after grafting, and samples were taken for electron microscopy. Eight grafts were examined in each series. Non-grafted extensor digitorum longus muscles from limbs that had been denervated for 4 or 14 days were also examined.

\section{RESULTS}

\section{Survival of muscle fibers}

Within $4 \mathrm{hr}$ of grafting, the muscle fibers could already be differentiated into two groups. Ischemic fibers, swollen and pale staining in survey sections, occupied most of the graft. Those muscle fibers that survived the ischemic period formed a thin rim around the periphery of the graft and maintained their normal dense staining and their polygonal shape (Fig. 1).

Although the surviving fibers remained structurally intact (Fig. 2), they assumed the general ultrastructural features of denervated muscle fibers during the next few days. The basal lamina always adhered closely to the sarcolemma of the fibers. "Ruffling" or duplication of the basal lamina was never observed. Satellite cells became enlarged and occasionally developed myofilaments. One feature, common in 


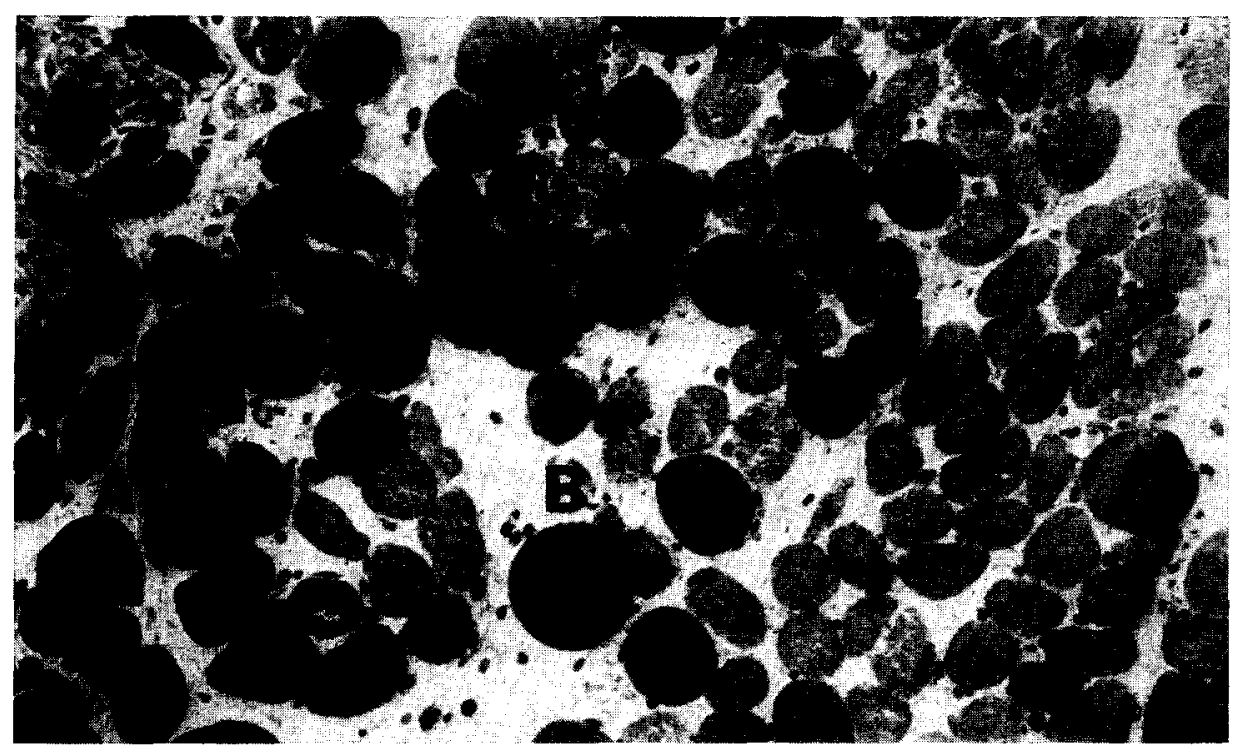

Fig. 1. Cross-section through a region at the periphery of a normal graft after one day. Densely stained fibers at left (zone A) have survived ischemia. Some of the surviving fibers contain numerous lipid droplets. Pale-staining fibers in center and at right (zone B) have become ischemic. $1 \mu \mathrm{m}$, toluidine blue, $\times 460$.

the surviving fibers of the graft, was not found in corresponding denervated but nongrafted muscles; large lipid droplets were prevalent, particularly in those surviving fibers which were most closely adjacent to the ischemic fibers (Figs. 1 and 2). The lipid droplets disappeared within 4-5 days after grafting. A small proportion of the surviving fibers underwent non-ischemic degeneration. They became rounded and densely stained, nuclei became pyknotic, and myofibrillar materials became distorted.

The diameters of the surviving fibers diminished during the first week after grafting. During this time, the survivors were easily distinguished from ischemic fibers on the basis of differences in staining density. However, after the necrotic fibers were phagocytized and new fibers had regenerated to the late myotube or immature fiber stage, the distinction became less clear. Because of their similarities in both size and staining properties, the surviving and regenerating fibers could not be distinguished from each other by light microscopy after 10 days.

\section{Degeneration and destruction of muscle fibers}

The ischemic fibers underwent two phases of destruction: an initial phase of intrinsic degeneration and a later phase of cell-mediated destruction.

\section{Intrinsic degeneration}

The initial degeneration was a response that occurred uniformly throughout the muscle within the first day after grafting (Figs. 3, 4). Most of the changes which occurred during this phase became evident as early as $4-8 \mathrm{hr}$ after grafting. The sarcolemma became fragmented and subsequently disappeared. Glycogen and ribo- 


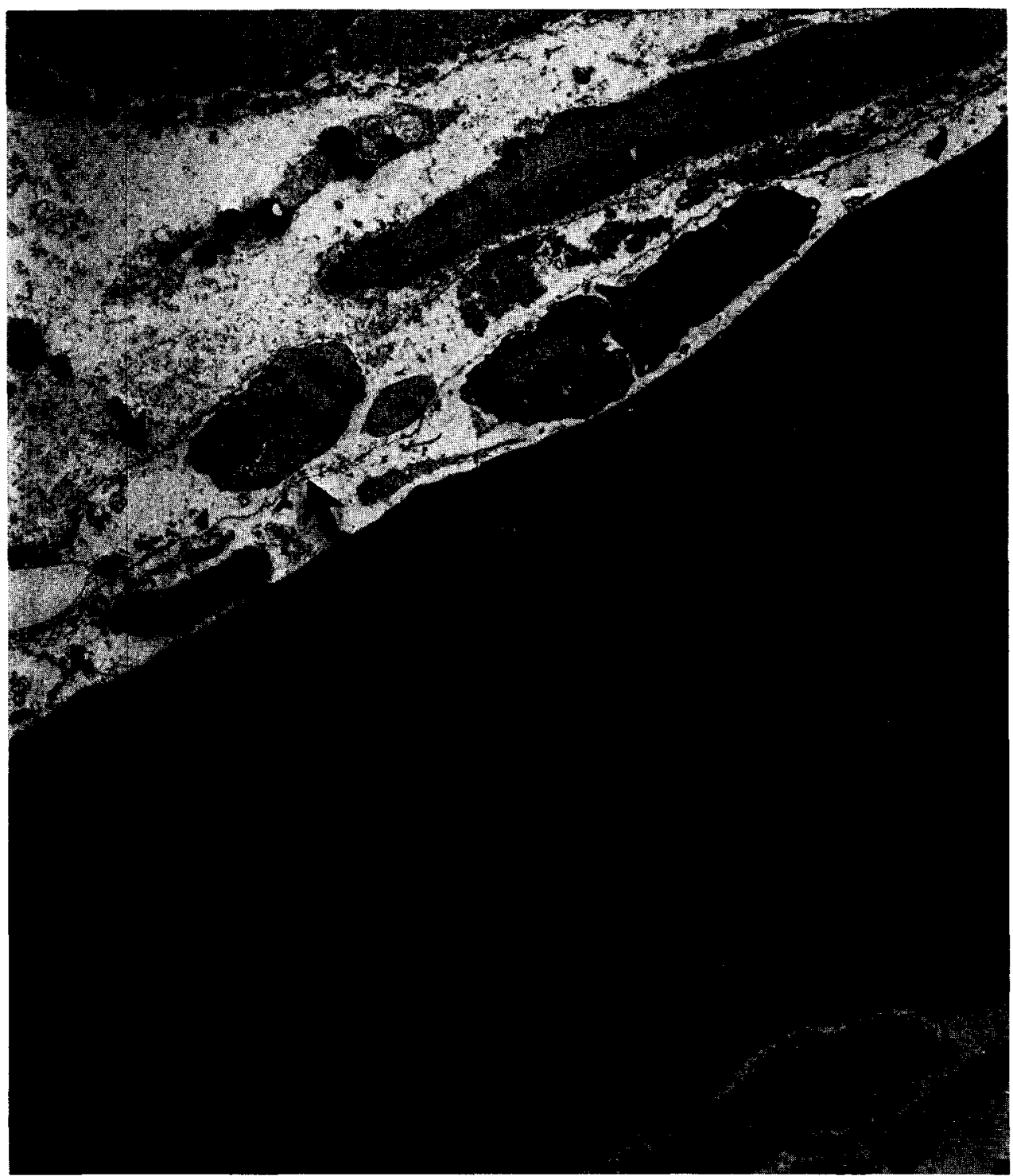

Fig. 2. Surviving fiber from a 4-day normal graft shows numerous lipid droplets and well-preserved myofibrils. A portion of a necrotic fiber $(\mathrm{N})$ and a basal lamina tube (arrows) whose contents have been phagocytized are also shown. $\times 3,400$.

somes also disappeared. Mitochondria became swollen and contained electron-dense deposits. The sarcoplasmic reticulum formed aggregates of swollen vesicles, whereas elements of the T-system could not be identified. Destruction of the myofibrillar material was marked by the dissolution of the Z-band, followed by separation of myofibrils into individual sarcomeres or coalescence of fibrils to form a homogeneous granular mass. The myonuclei underwent karyolysis within $24 \mathrm{hr}$. The basal laminae of the muscle fibers remained largely intact (Fig. 4), but in some regions the basal 


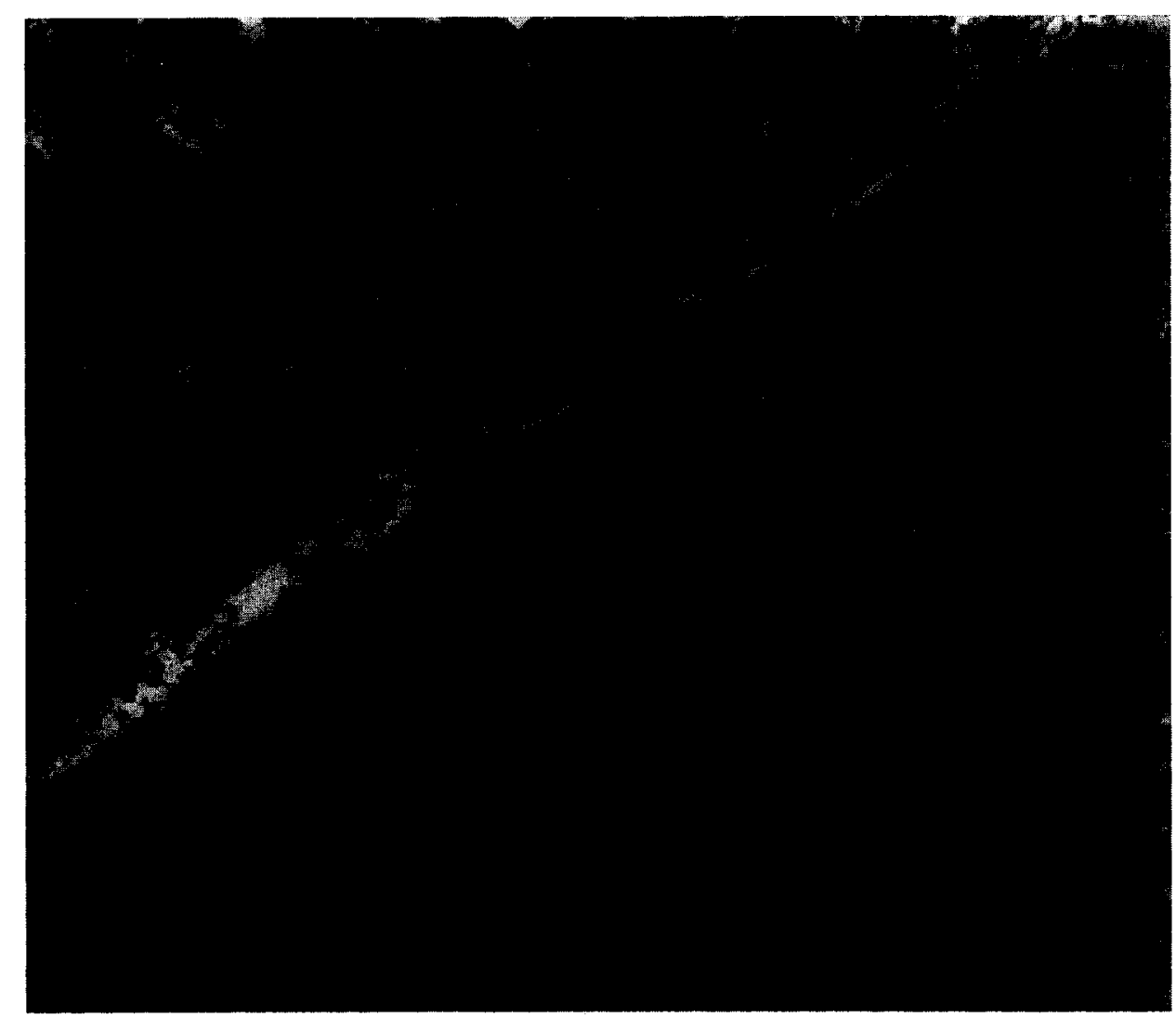

Fig. 3. Ischemic fiber (upper left) from a 1-day normal graft shows loss of Z-bands and myofibrillar disruption. Swollen mitochondria contain electron-dense deposits. Nuclear membrane is disrupted. $\times 5,600$.

laminae became fuzzy or indistinct. Occasional discontinuities in the basal laminae were also noted. Satellite cells, present in small numbers, were the only viable cells found within the basal laminae of the original muscle fibers after the initial degenerative reaction occurred (Fig. 4). At this time, the satellite cells were small and elongated; they contained few organelles; and their nuclei were flattened and heterochromatic. There was no evidence linking original myonuclei to the formation of satellite-like cells. No further change in the state of the degenerating fibers occurred until cellmediated destruction began.

\section{Cell-mediated destruction}

Neutrophils were the first externally-derived cells found within the basal laminae of the degenerating muscle fibers, but there was little evidence of any substantial phagocytosis by these cells. The major destruction of the original fibers was mediated by macrophages. When prephagocytic cells first appeared within the basal laminae of the original fibers, 2-3 blunt, elongated pseudopodia were usually visible in the plane of section giving them a stellate appearance (Fig. 5). Their pseudopodial extensions 


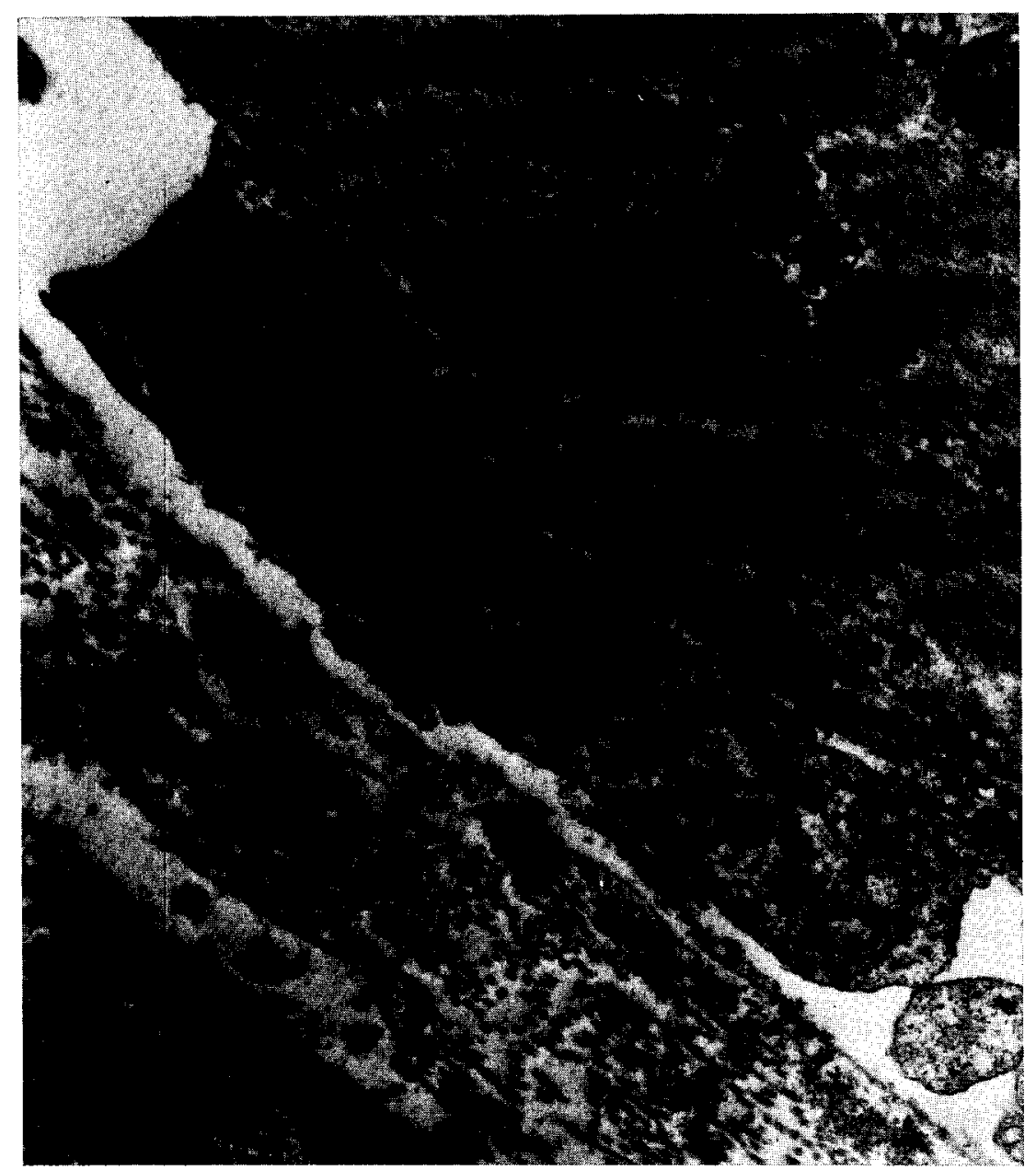

Fig. 4. Satellite cell in an ischemic fiber from a 2-day normal graft. The sarcolemma of the fibers has disappeared, but the basal lamina persists (arrow). $\times 9,900$.

enveloped large regions of debris. As the cellular debris was digested, the cells became smaller and developed numerous long, thin pseudopodia (Fig. 7). Some of these macrophages remained within the basal lamina during the early period of regeneration.

Changes occurred in the satellite cells concurrently with cell-mediated destruction of the original muscle fibers (Figs. 5 and 6). They became enlarged and developed large, euchromatic nuclei with prominent nucleoli. Such cells, characterized by dense accumulations of ribosomes and an absence of both myofilaments and enveloping basal laminae, were defined as presumptive myoblasts. During the earliest stages of cell-mediated destruction it was sometimes difficult to distinguish between satellite cells or presumptive myoblasts and pre-phagocytic cells, particularly when the cells were situated near the basal lamina. In general, the nuclei of pre-phagocytic cells were more heterochromatic and irregular in shape than those of presumptive myoblasts. 


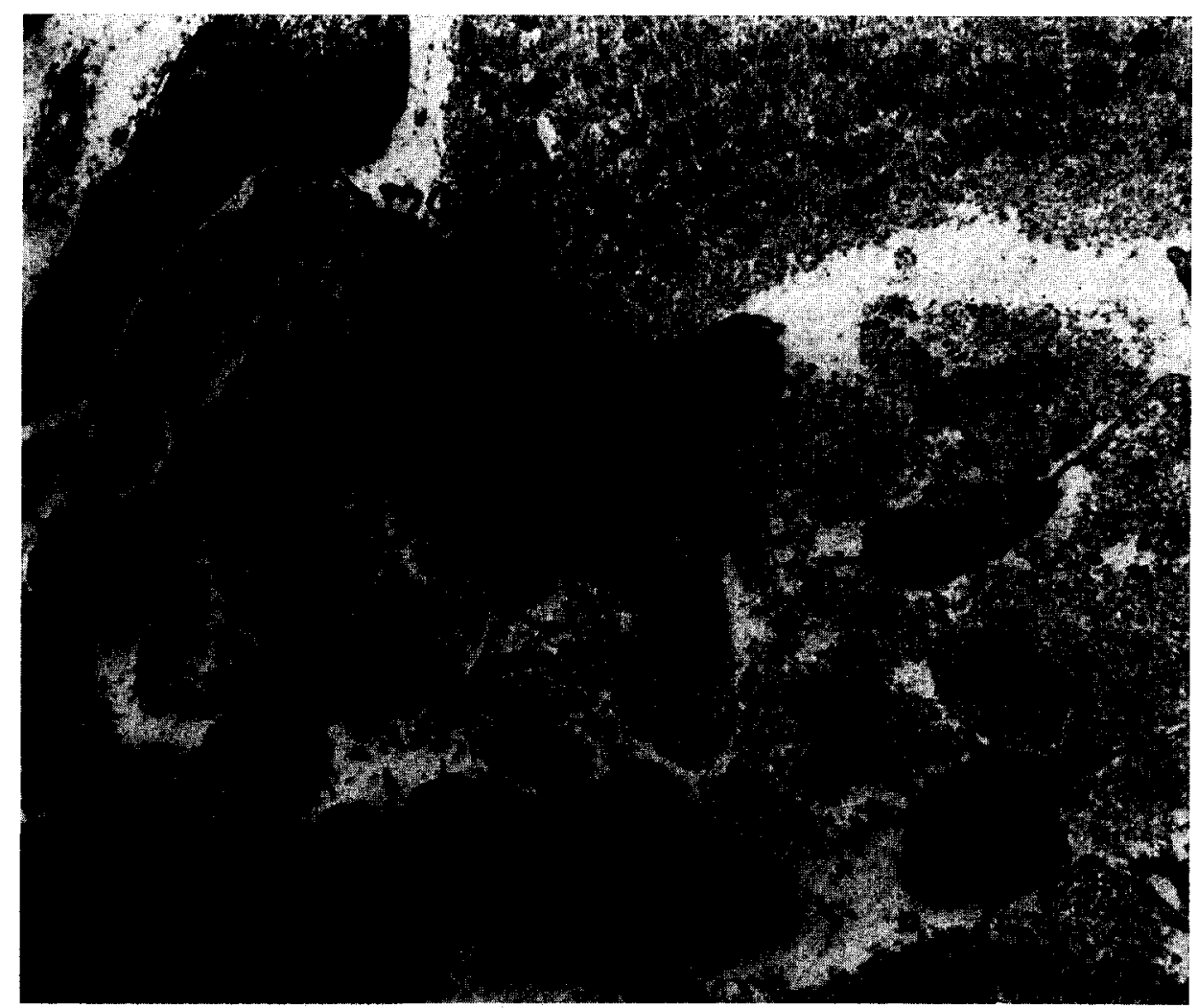

Fig. 5. Fragmenting fiber from a 1-day pre-denervated graft contains a presumptive myoblast (PM), a macrophage $(\mathrm{M})$, and a neutrophil $(\mathrm{NP}) . \times 4,700$.

The cytoplasm of pre-phagocytic cells was more electron-dense than presumptive myoblasts and lacked the characteristic ribosomal clusters. However, cells with intermediate characteristics were observed within the basal lamina and could not be positively identified.

At the completion of the phase of cell-mediated destruction, the original myofibrillar and sarcoplasmic contents of the fibers had been phagocytosed, leaving only the original basal laminae. The cells remaining within the original basal laminae at this time were presumptive myoblasts, occasional neutrophils, and macrophages (Fig. 7).

\section{Early regeneration}

Regeneration of muscle fibers began as phagocytosis of the original fibers neared completion. The presumptive myoblasts rapidly proliferated to form a nearly continuous chain of cells along the inner surface of the basal lamina, which served as a structural framework for regeneration. Although the presumptive myoblasts had sometimes assumed an irregular shape during the period of cell-mediated destruction, they were consistently spindle-shaped after the cell debris had been removed. Presumptive myoblasts undergoing mitosis (Fig. 7) were occasionally observed. 
The transition between presumptive myoblasts and true myoblasts was marked by the production of myofilaments (Fig. 8). Individual myoblasts fused to form multinucleated myotubes. The earliest sarcomeres of the myotubes were formed near the periphery of the cell. Rudimentary aggregates of sarcoplasmic reticulum appeared at this time. Diads, triads and pentads also appeared, but did not become specifically aligned near the myofibrils until later. Autophagic vacuoles were commonly found in the myotubes.

The formation of myotubes followed a biphasic pattern on development. A "primary" myotube was formed by the fusion of several myoblasts. Other presumptive myoblasts, however, remained associated with the "primary" myotube and did not differentiate until later. Portions of one or more undifferentiated cells were nearly always evident in transverse sections through myotubes during this period of regeneration (Fig. 9). These latter presumptive myoblasts secondarily developed into myotubes alongside the primary regenerating fiber within the original basal lamina. As the "primary" and "secondary" myotubes matured, new basal lamina was deposited

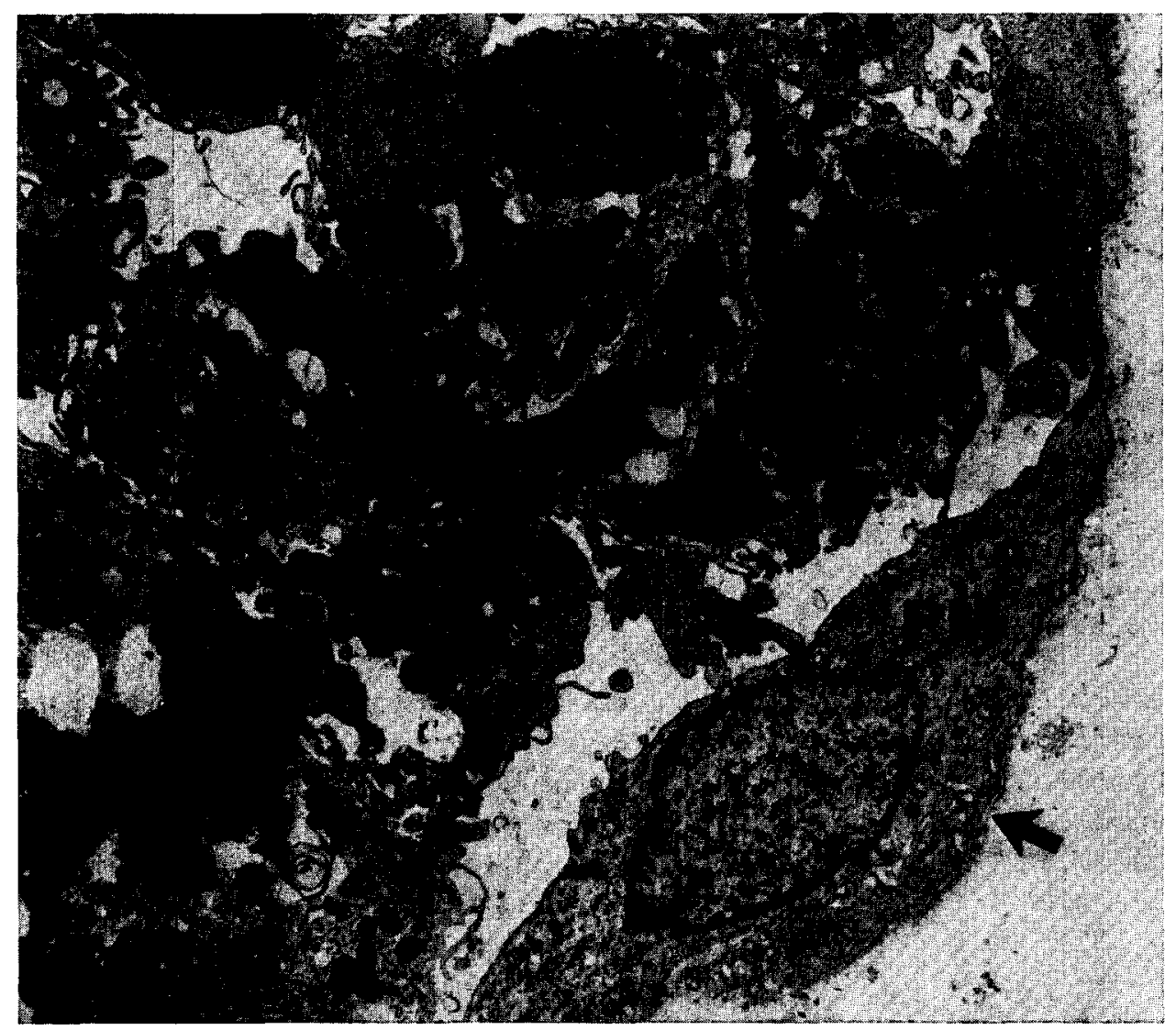

Fig. 6. Fragmenting fiber from a 6-day normal graft. Presumptive myoblasts (PM) line the original basal lamina (arrow). The necrotic debris $(N)$ of the original fiber has been engulfed by macrophages. $\times 4,700$. 


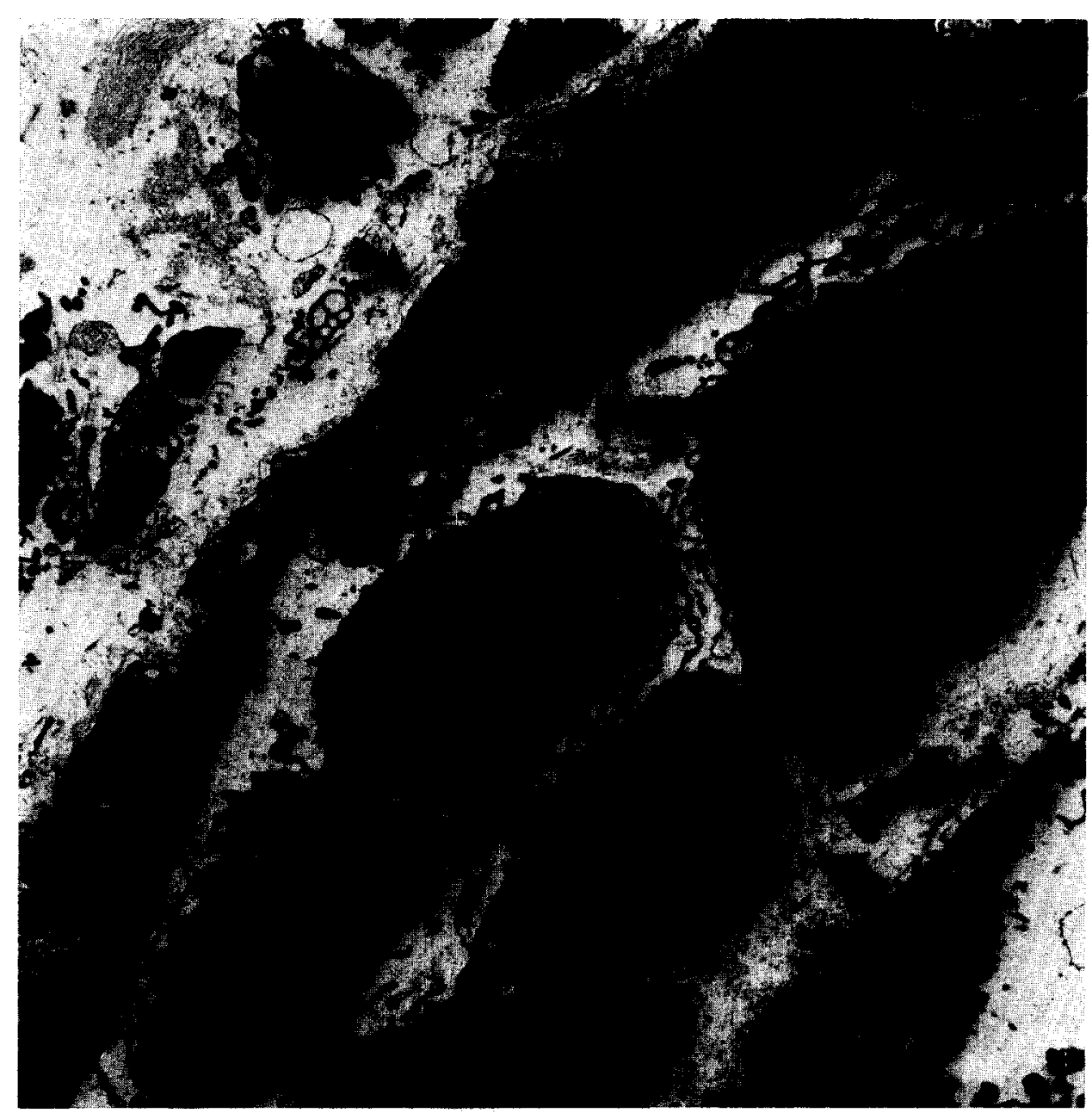

Fig. 7. Cells within the original basal lamina (arrows) of a 4-day normal graft. Presumptive myoblasts (PM) line the basal lamina. One of the presumptive myoblasts is undergoing mitosis. Macrophages (M) are also present within the basal lamina. $\times 4,800$.

on surfaces which did not directly contact the original basal lamina. This process eventually separated the primary and secondary fibers from one another (Fig. 10). Removal of the redundant original basal lamina began soon after the new lamina was deposited. There was no evidence of direct phagocytosis of the original basal laminal material. In most regions the layers simply became diffuse and appeared to disintegrate.

The formation of new myotubes was not entirely confined to the interiors of preexisting basal laminae, because the grafts contained occasional myoblasts and myotubes around which the basal lamina was either lacking (Fig. 11) or present only over a limited region of the surface. Presumptive myoblasts associated with some primary myotubes appeared to be largely separated from the myotube and its basal 
lamina (Fig. 12). Myotubes lacking basal laminae were found both among other regenerating muscle fibers and within areas of connective tissue. In some cases, regeneration appeared to be completely independent of any basal laminae. In other cases, it was impossible to determine with certainty whether these myotubes had developed outside the original basal lamina or whether they were simply at an intermediate stage in which the original basal lamina had been removed but a new one had not yet completely formed.

\section{Maturation of regenerating fibers}

As the myotubes matured into myofibers, many, but not all of the centrally located nuclei migrated to the subsarcolemmal position. The nuclei of the maturing fibers were smaller and more elongated, and contained more heterochromatin than the nuclei of the myotubes. The myofibrils gradually became more densely packed, and inter-fibrillar ribosomal clusters became less extensive. T-tubules sometimes continued to be oriented parallel to the myofibrils instead of at right angles. The convergence between the progressive differentiation of the regenerating muscle fibers and the

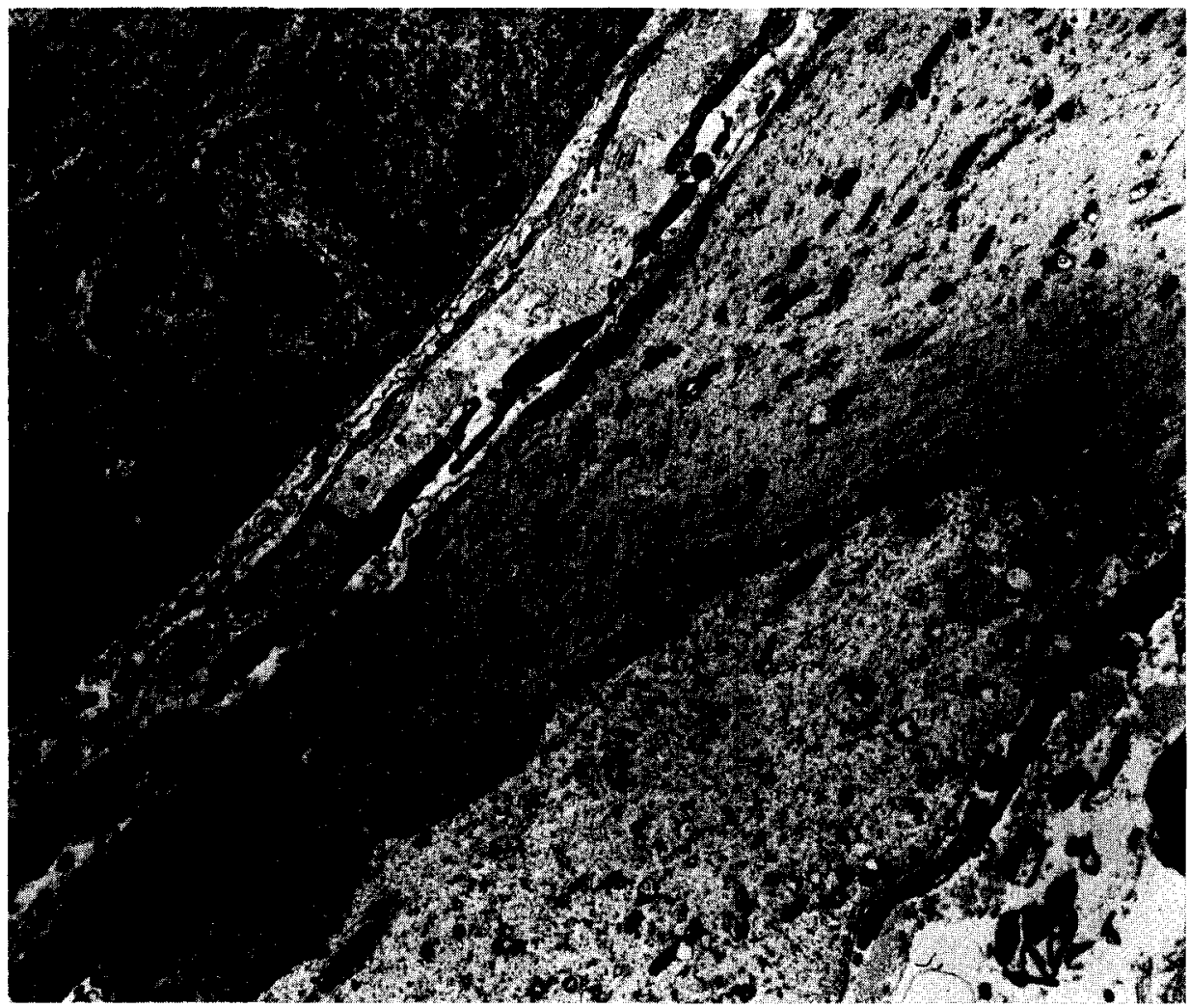

Fig. 8. Two myoblasts within the original basal lamina (arrows) of a fiber from a 5-day normal graft, showing early assembly of myofilaments into myofibrils (My). A presumptive myoblast (PM) is also within the same basal lamina. An adjacent fiber has regenerated within the original basal lamina and has synthesized a new basal lamina (BL) within the original lamina. $\times 4,000$. 


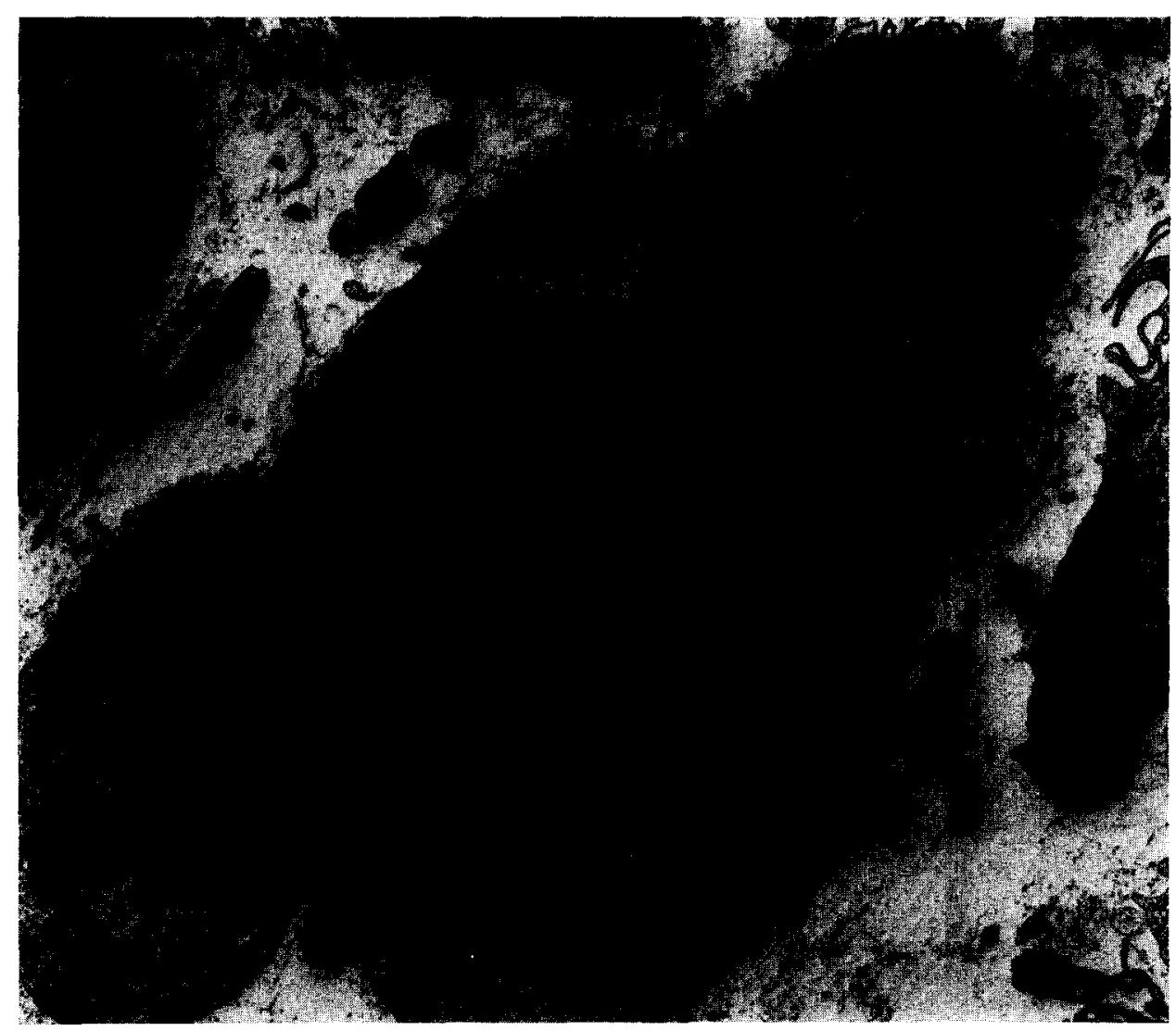

Fig. 9. A primary myotube (MT) and associated presumptive myoblast (PM) within a common basal lamina (arrows) in a 6-day normal graft. $\times 4,200$.

regressive changes of the still denervated, surviving muscle fibers made it difficult to separate the two populations after 10 days.

Morphological distinction of fiber types became evident after the regenerating muscle fibers had matured. Although small subsarcolemmal clusters of mitochondria were found in many fibers by 30 days, a clearer distinction between "mitochondriarich" (Fig. 13) and "mitochondria-poor" fibers became apparent by 60 days after grafting. Fiber types could also be distinguished by the width of the Z-bands. The widths of the Z-bands ranged from approximately 70 to $93 \mathrm{~nm}$ in immature fibers. In contrast, those of the mature (60-day) regenerates were identical to controls, which had 2 distinctly different size ranges, approximately 47 and $70 \mathrm{~nm}$.

Except for the presence of centrally located nuclei, the vast majority of the fibers in the maturing and mature grafts were morphologically normal. Commonly, however, myo-myous junctions joined adjacent fibers laterally or joined two fibers end-toend (Fig. 14). The interdigitating structure of the junction was similar to that of a myotendinous junction, but instead of having collagen adhering to the basal lamina, another fiber was attached. Fibers in which these myo-myous junctions were found 


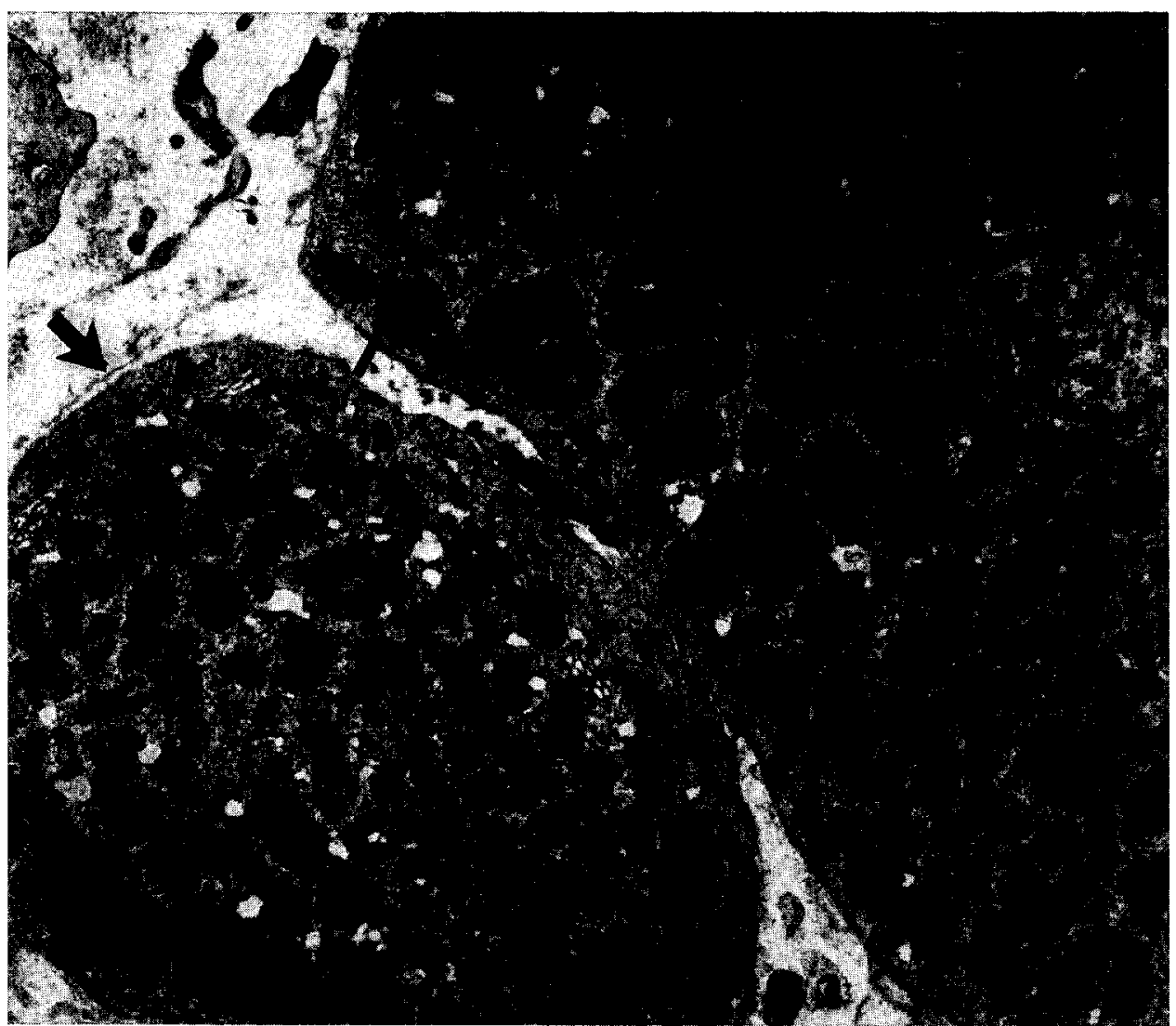

Fig. 10. Two regenerating fibers from a 10-day Marcaine-treated graft. Both fibers were originally enveloped by a common basal lamina (arrow) from the original muscle fiber, but they are now undergoing separation as new basal lamina (BL) becomes deposited between them. $\times 6,500$.

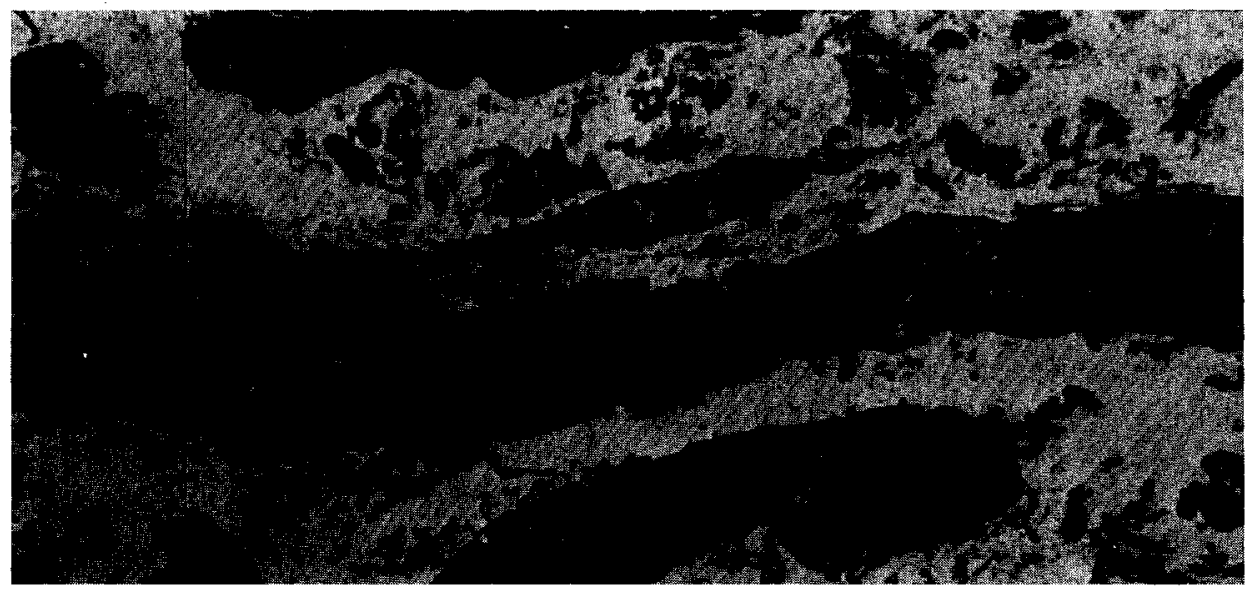

Fig. 11. Myoblast (MB) and presumptive myoblasts (PM) aligned in the interstitium of a 6-day normal graft. The cells are outside of and independent of the original basal laminae of any of the fibers. $\times 6,700$. 


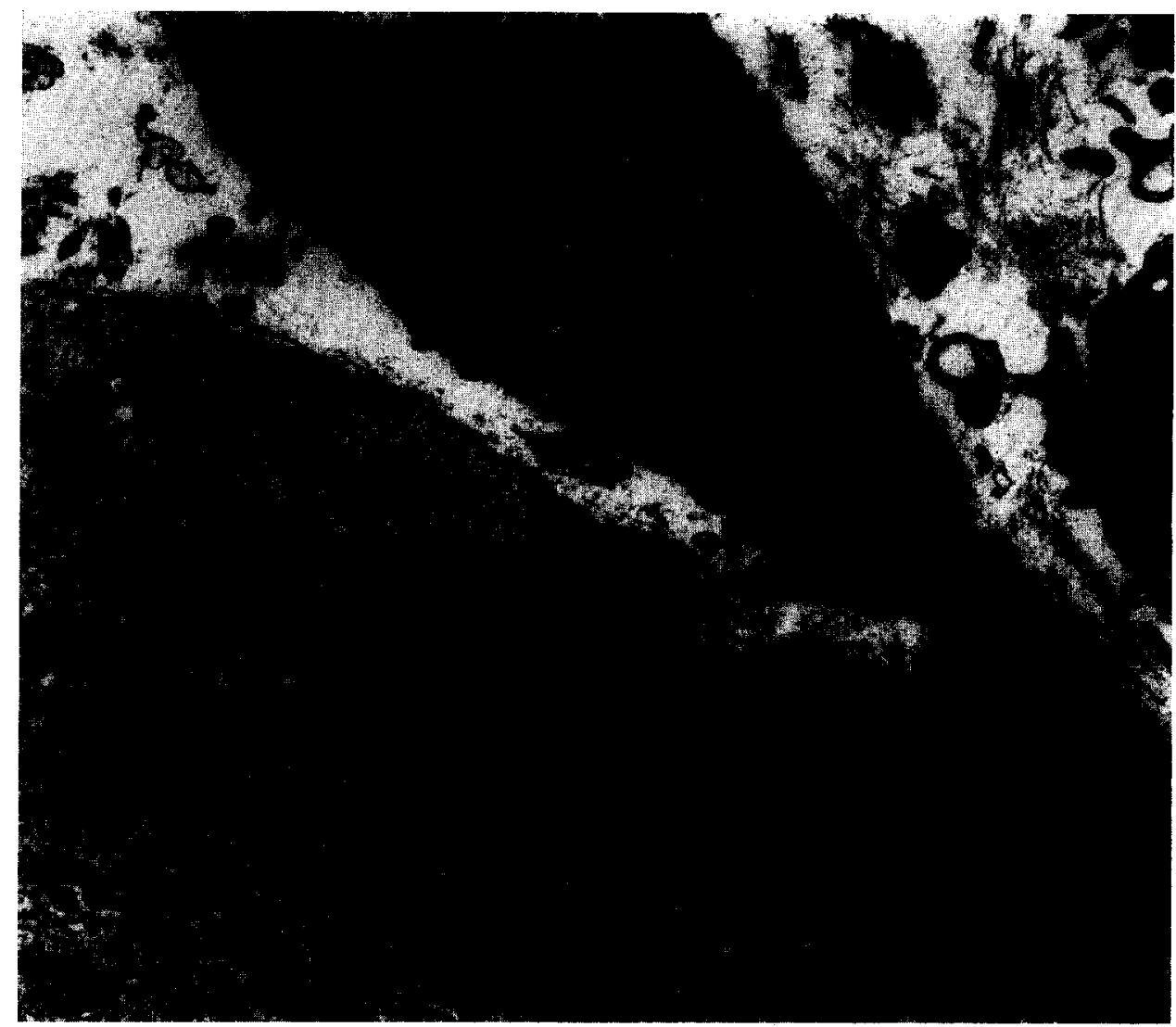

Fig. 12. Portion of a myotube (MT) and two presumptive myoblasts (PM) from a 6-day normal graft. One of the presumptive myoblasts extends outside of the original basal lamina (arrow), into the interstitial space. $\times 6,900$.

appeared to be normal in size and structure. It was impossible to determine the frequency of myo-myous junctions, but as a relative index, they were found in all the mature grafts and one or more examples, often in clusters, could be found in about half the survey sections from each animal.

\section{Interstitial cells}

The first day after grafting was characterized by an almost complete lack of viable cells within the interstitium, even around the surviving fibers (Fig. 1). The profile of cells within the degenerating fibers changed concurrently with the influx of cells into the interstitium. Neutrophils were found among both the survivors and the peripherally located ischemic fibers after the first day. A wave of these cells moved toward the center of the graft well in advance of the ingrowing blood vessels. Lymphocytes were present at approximately the same time, although they were fewer in number than the neutrophils. Monocytes, or pre-phagocytic cells, moved into the interstitial spaces of each region subsequent to the appearance of neutrophils. Overt macrophages with prominent pseudopodia became most evident in each region only when cell-mediated destruction of nearby fibers neared completion. 
Macrophages were still present in many of the original basal lamina tubes when regeneration began. Once the new basal laminae of myotubes were formed, the macrophages became spatially isolated from the regenerating fibers, but unlike neutrophils, they remained numerous in the interstitial spaces for several days afterward. When found outside the original basal laminae, the macrophages never contained recognizable debris from the adjacent phagocytized fibers. Macrophages gradually decreased in number and were rarely found after 30 days. Monocytes, lymphocytes, and rare eosinophils were also found during this period. Mast cells were occasionally observed in association with connective tissue or blood vessels during the early regenerative stages and in maturing muscle.

Large, highly active fibrocytes were dominant in the interstitial spaces during the earliest phase of regeneration, but they rapidly decreased in size and number. Collagen deposition in the interstitium increased as myotubes were formed and began to mature. Collagen and fibroblasts were sometimes also found inside the original basal laminae of the muscle fibers. Although most regions of the regenerated muscle were free of excessive collagen deposits, some regions, particularly those near the perimysial sheath, developed larger accumulations of collagen, which tended to envelop individual muscle fibers.

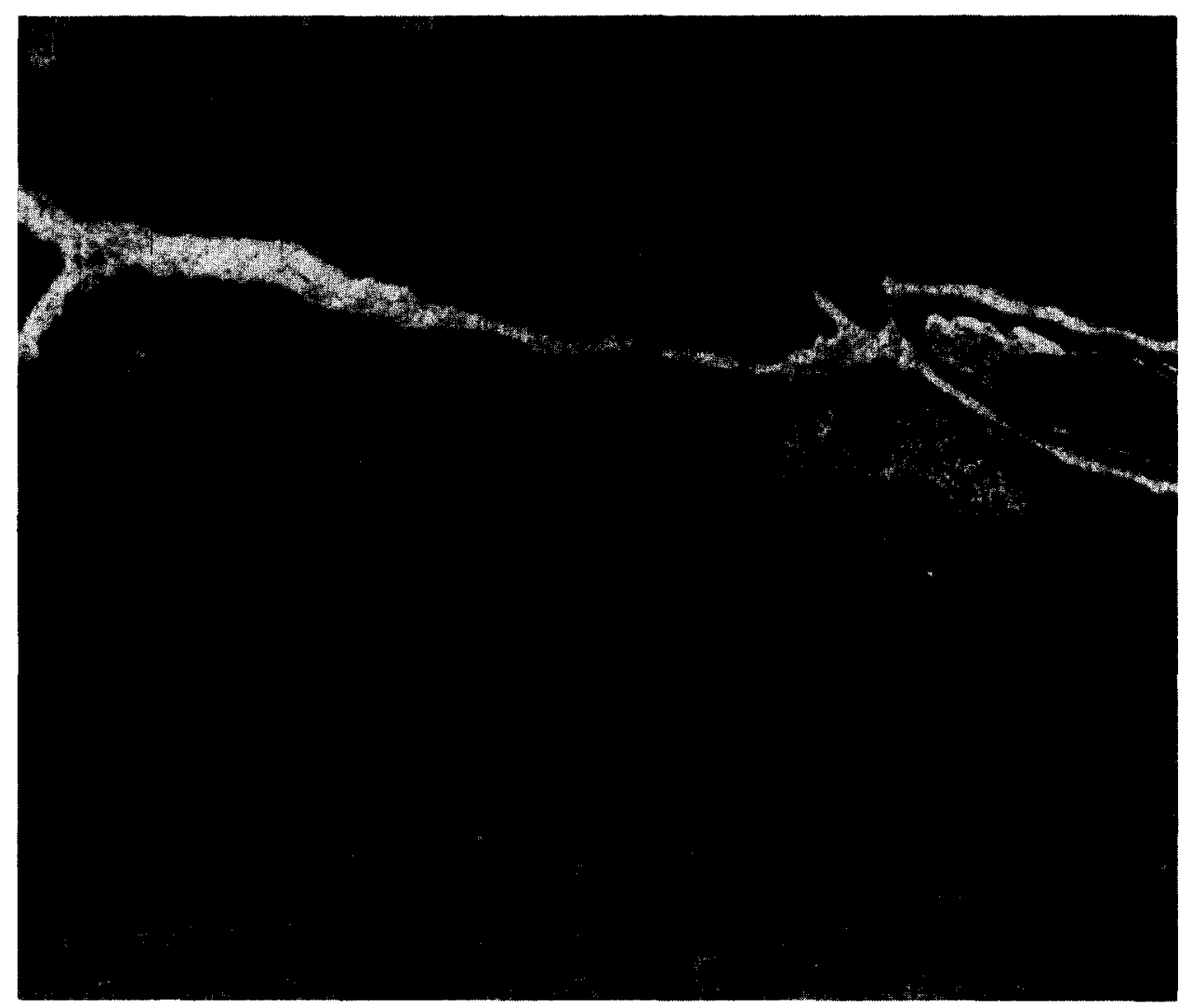

Fig. 13. Mitochondria-rich fibers in a 120-day normal graft. A myonucleus (N) and a satellite cell (SC) are present. $\times 5,700$. 


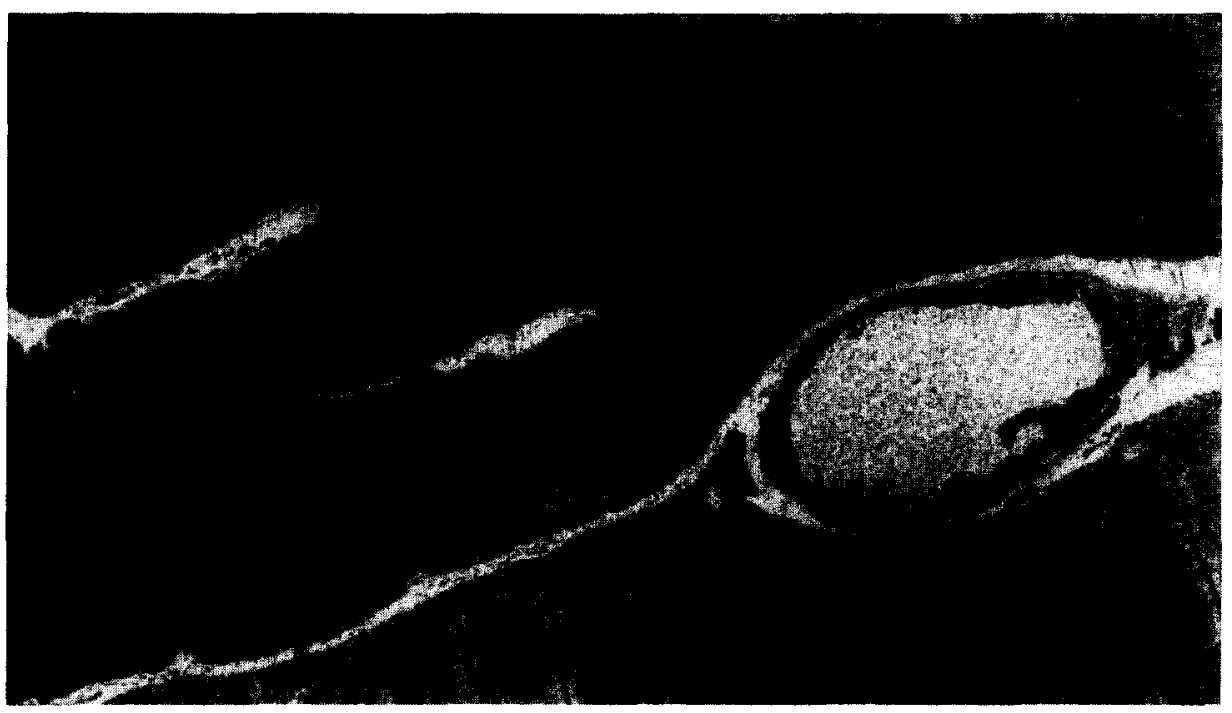

Fig. 14. Myo-myous junction joining two fibers laterally in a 60-day normal graft. Adjacent regions of the fibers are separated by a single layer of basal lamina (arrows). $\times 4,900$.

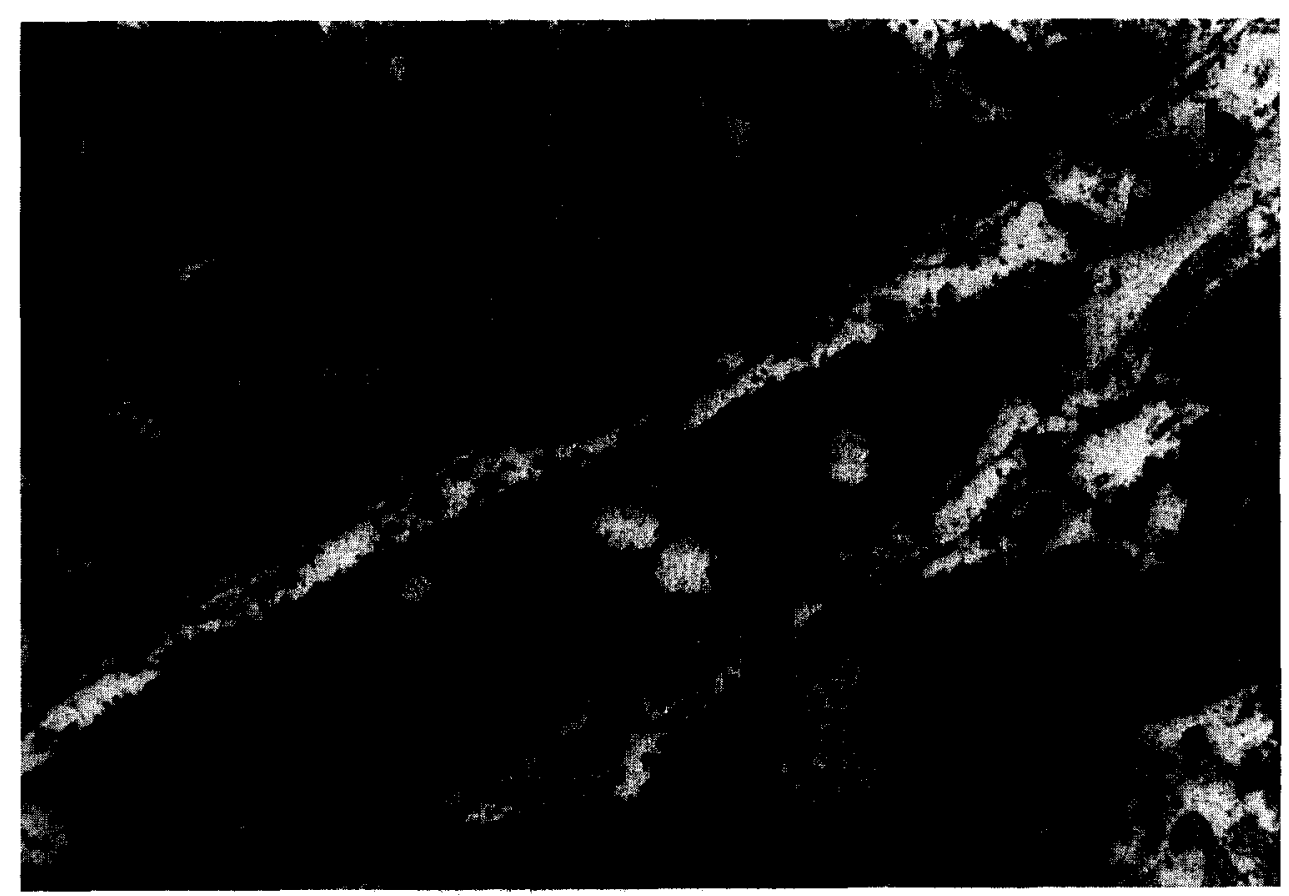

Fig. 15. Interstitial cell (IC) in a 4-day normal graft is identical to the presumptive myoblast (PM) within the basal lamina of an adjacent fragmenting fiber. Basal laminae of 3 fibers $(a, b, c)$ are indicated by arrows. $\times 6,100$, 
Endothelial cells and fibrocytes associated with developing blood vessels (Fig. 2) were prevalent at the periphery of the graft by the third day and subsequently moved toward the center of the graft. Blood vessels were seldom observed immediately adjacent to muscle fibers when they were initially infiltrated with pre-phagocytic cells, but soon thereafter they were present in areas of active cell-mediated destruction of ischemic muscle. Some of the endothelial cells bore a close morphological similarity to presumptive myoblasts. In addition, cells identical to presumptive myoblasts but not associated with the developing blood vessels were observed in the interstitium (Fig. 15).

\section{Spatial and temporal relationships within the graft}

The general sequence of cellular events in muscle degeneration and regeneration was the same in all regions of the graft. However, these changes followed a definite spatial and temporal pattern, as depicted schematically in Fig. 16. Except for the thin outer ring of surviving fibers, all the fibers within the grafted muscle underwent the initial intrinsic degeneration simultaneously, and thereafter remained morphologically stable until they were invaded by neutrophils and macrophages. Cell-mediated destruction of the degenerating fibers began in the peripheral fibers on the second day after grafting. This phase of destruction moved concentrically toward the center of the graft during the subsequent 3-4 days.

The formation of myoblasts first occurred at the periphery, just inside the zone of surviving fibers, within 3 days after grafting. By the 4th day, many fibers in the peripheral zone had formed myotubes. At this time, the interior regions of the graft were still undergoing degeneration. While the outermost myotubes began to mature into myofibers, regeneration was being initiated more centrally in the graft. Myotubes were present in the center of the graft by the end of the first week after grafting. Spatial separation of the primary and secondary myotubes was most prevalent $7-10$ days after grafting, but the process was also observed during the next two weeks as the myotubes matured.

The myotubes and immature myofibers were initially round when observed in transverse sections, but by 6-7 days after grafting, many of the peripherally located fibers began to assume a polygonal shape (Fig. 17). A clear spatial separation into fascicles was evident by the 10th day. At this point, the graft consisted of fibers of a variety of sizes. The outermost fibers, the "survivors", were the largest. However, there was no clear demarcation between these and regenerating fibers, since a mixture of sizes was observed. Fiber sizes were smaller toward the center of the graft. By 30 days after grafting the fibers were larger and generally fairly uniform in size. A major increase in fiber size occurred between 30 and 60 days, with little further enlargement thereafter (Fig. 17). A sub-population of very thin atrophic fibers, either in small groups or entire fascicles, became more evident in the 60-day grafts. Fibers in longterm grafts differed little in size or appearance from those at 60 days.

\section{Pre-denervated and Marcaine-treated grafts}

Pre-denervation of the grafts resulted in a larger proportion of surviving muscle 


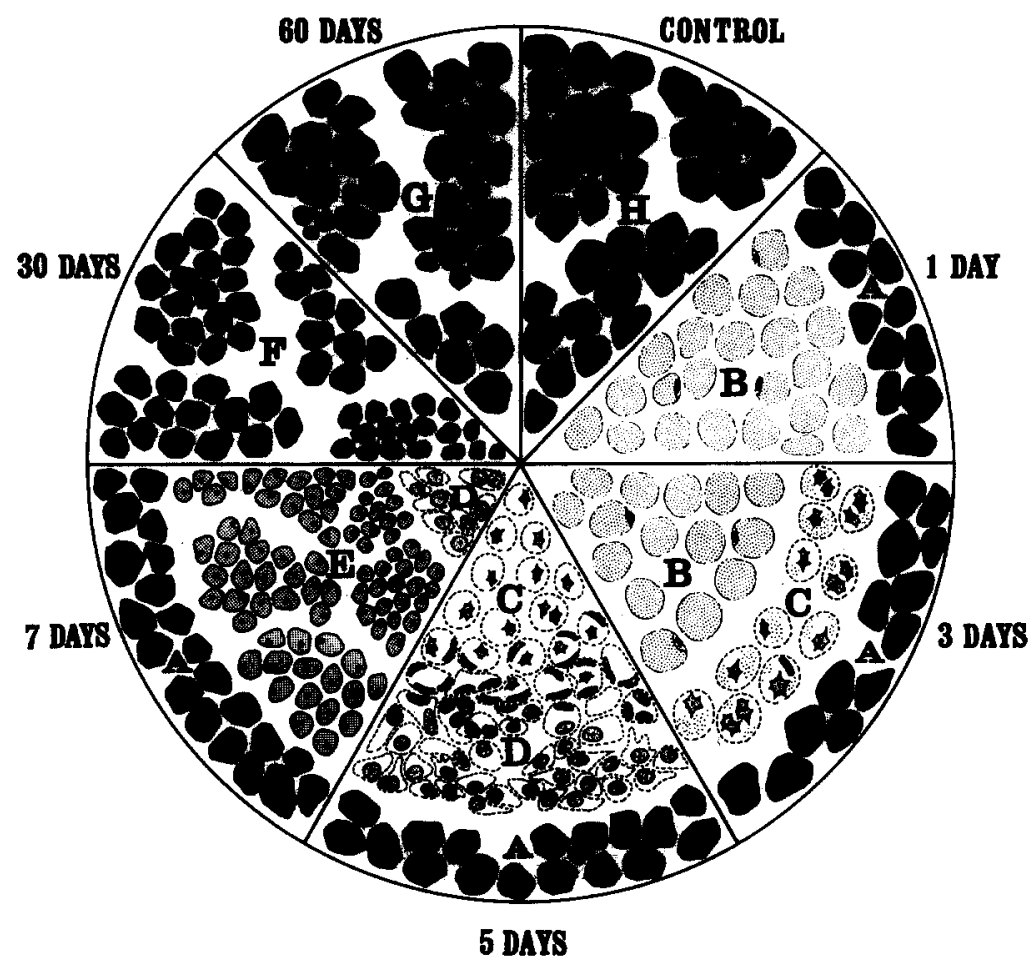

Fig. 16. A schematic representation of a cross-section through an entire muscle graft. Each wedge represents the histological changes, from the periphery to the center of the graft, at different time intervals. Prior to grafting, the population of fibers throughout the muscle is homogeneous in size and shape (zone $\mathbf{H}$ ).

One day after grafting, two distinct populations of fibers are evident. Fibers at the periphery of the graft (zone A) have survived ischemia. These fibers can be distinguished from the interior fibers throughout the first week. The majority of fibers in the graft undergo an intrinsic destruction as a result of ischemia (zone B). Some of the satellite cells from the original fibers survive.

By the 3 rd day after grafting, the periphery of the graft has become revascularized. Macrophages penetrate the necrotic fibers, initiating the phase of cell-mediated destruction (zone C). Phagocytosis of the necrotic debris leaves only satellite cells (presumptive myoblasts) and the basal lamina from the original fibers. No changes are yet evident in the interior of the graft (zone B).

On the 5 th day after grafting, the region of cell-mediated destruction (zone $C$ ) has reached the interior of the graft. Regeneration of new fibers is underway more peripherally. Zone D represents the region in which myoblasts and primary and secondary myotubes, predominantly within the original basal lamina, are found.

At the end of the first week the graft consists of surviving fibers (zone A), immature regenerating fibers (zone E), and myotubes (zone D). The entire 30-day graft contains maturing fibers (F), with a gradient of size between periphery and center. In the 60-day graft the fibers have reached a stable state (zone G). Innervated fibers are comparable to control fibers in size and appearance. Clusters of atrophic, presumably non-innervated fibers are interspersed among the normal fibers.

fibers than was found in normal grafts. The fibers were smaller than the survivors in normal grafts but they were comparable to non-grafted muscle which had been denervated for the same period of time. The surviving fibers of pre-denervated grafts were otherwise identical to those of the normal grafts. Cell-mediated destruction of muscle fibers within the pre-denervated grafts proceeded more rapidly than in normal 

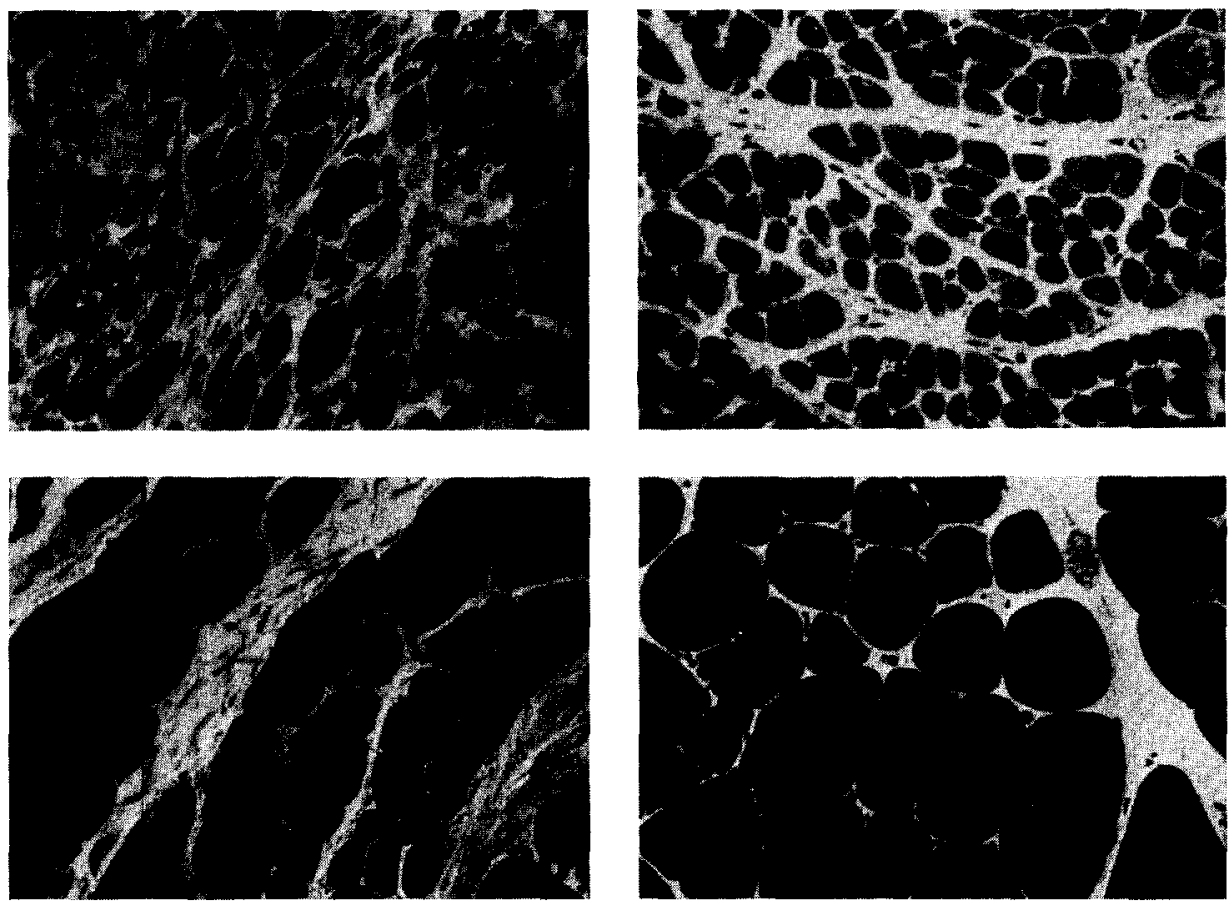

Fig. 17. Transverse sections through regions of 7,10,30 and 60-day normal grafts illustrate changes in size and organization of fibers regenerating within the grafts. $\times 360$.

grafts. By the first day, the interstitium and many of the injured fibers within the thick ring of surviving fibers had been infiltrated by neutrophils and pre-phagocytic cells (Fig. 5). Some, but not all of the satellite cells were more elongated than those seen on the first day after grafting in normal muscle, and they commonly assumed the features of presumptive myoblasts (Fig. 5). By the fourth day after grafting, all the injured fibers examined had been either completely phagocytized or at least invaded by pre-phagocytic and phagocytic cells, whereas cell-mediated destruction had not yet begun in many fibers in the central regions of 4-day normal grafts.

No surviving muscle fibers were found in the Marcaine-treated grafts. The ultrastructural appearance of fragmenting fibers in the Marcaine-treated grafts was identical to that in normal grafts. Both the rate of progression of cell-mediated destruction and the appearance of satellite cells inside the ischemic fibers were comparable to that of normal grafts.

The initial regenerative response was accelerated in the pre-denervated grafts. By the 4th day after grafting, essentially the whole of the regenerating area of the graft consisted of myotubes or basal lamina tubes containing enlarged myoblasts and presumptive myoblasts. In contrast, the initial regenerative response of the Marcainetreated grafts followed a time course very similar to that of normal grafts. There were no other discernable differences in the course of regeneration or maturation between normal grafts and pre-denervated or Marcaine-treated grafts. By 30 days the muscle 
fibers in both pre-denervated and Marcaine-treated grafts were indistinguishable from those in normal grafts.

\section{DISCUSSION}

The grafted muscle is initially ischemic. As a result, the majority of muscle fibers are irreversibly injured and begin to break down. However, some of the peripheral fibers survive the initial ischemia. These fibers are responsible for the weak contractile responses that have been recorded during the early days after grafting, when the remainder of the muscle is degenerating and cannot possibly contract (Carlson and Gutmann 1975b). Nearly all the changes found in the surviving fibers are characteristic of denervated muscle (Cullen and Pluskal 1977). The presence of large lipid droplets in surviving fibers of both the normal and denervated graft, however, has not been previously reported. Since lipid accumulation is prevalent only in the inner layer of surviving fibers, its appearance may be indicative of a marginal metabolic state due to barriers to the diffusion of oxygen to that depth. Impairment of lipid oxidation has been reported in denervated extensor digitorum longus muscle (Kerner et al. 1976). Deficiency in the oxygen supply may exacerbate the condition, resulting in an accumulation of lipid. The lipid droplets are no longer evident after the region becomes revascularized.

The factors which promote the survival of muscle fibers are not clear. A reduction in the level of glycolytic and oxidative metabolism as a result of denervation (Hogan et al. 1965) may facilitate survival. Another possibility is that the reduced size of a pre-denervated graft may permit a greater number of muscle fibers to receive adequate amounts of oxygen and substrate by diffusion. Although of theoretical interest, resolution of the question is probably not critical to the problem of understanding the basic mechanism by which the graft becomes functional in the host because the contribution of surviving fibers to the total fiber number in regenerated grafts is of relatively little long-term significance (Carlson 1976).

Ischemic fibers undergo intrinsic degenerative changes very soon after grafting. The ultrastructural appearance of the ischemic fibers in these grafts corresponds to that previously described in other grafts (Trupin 1973; Schiaffino et al. 1975; Mastaglia et al. 1975; Snow 1977a,b). Identical changes have also been described in non-grafted skeletal muscle after 2 or more hr of ischemia (Mäkitie and Teräväinen 1977). Histochemical studies of muscle made ischemic by grafting or mincing have shown a rapid loss of glycogen and phosphorylase activity (Snow 1973; Neerunjun and Dubowitz 1974; Carlson and Gutmann 1975a). The rapid drop in phosphorylase has been confirmed biochemically (Wagner et al. 1977). Other glycolytic enzymes also show a pronounced decline during the ischemic period after free grafting of a muscle (Wagner et al. 1977; Magon et al., unpublished). Marked mitochondrial disruption was observed in the necrotic muscle fibers in the present study. This confirms the suggestion (Snow 1973) that histochemical demonstrations of persistent oxidative enzyme activity in necrotic muscle may be an artifact related to the loss of integrity of the mitochondrial membranes. 
Once the initial irreversible changes occur, there is no further progression of destruction of the ischemic muscle fibers until phagocytic cells move in. Ingrowing blood vessels deliver pre-phagocytic cells, which migrate into the surrounding interstitium and penetrate the muscle fibers. The preliminary stage of cell-mediated destruction (i.e., the first appearance of neutrophils and pre-phagocytic cells within the degenerating fibers) occurs slightly before the arrival of blood vessels in the immediate area. These cells are assumed to have migrated out from the ingrowing blood vessels.

Cell-mediated destruction of the irreversibly injured fibers seems necessary for regeneration of new muscle to occur. A moderate capacity for phagocytosis by satellite cells or presumptive myoblasts has been reported (Allbrook 1962; Vracko and Benditt 1972; Trupin 1973; Yarom et al. 1976). However, experiments in which muscle was isolated from blood-borne cells indicate that the population of cells within muscle tissue, including satellite cells and interstitial cells, lacks the capacity for complete phagocytosis of the injured fibers (Carlson and Hansen-Smith, unpublished observations). Thus, externally-derived phagocytic cells play an important role in facilitating regeneration. Monocytes appeared to be the primary source of phagocytic cells. However, the modulation of cell shape and cytoplasmic contents of the cells inside the muscle fibers often prevents accurate identification. Distinction between pre-phagocytic cells and myogenic cells which had not attained the specific features characteristic of presumptive myoblasts (i.e., densely packed ribosomes and enlarged, euchromatic nuclei) was particularly difficult in this study.

Although presumptive myoblasts and pre-phagocytic cells appeared at about the same time in the fragmenting fibers, the possibility that the presumptive myoblasts become "activated" by the presence of phagocytic cells seems unlikely. It is more probable that this correlation is related to the arrival of a blood supply near the region. Work by Bischoff (1975), using cultured muscle fibers, shows that presumptive myoblasts form in the absence of either interstitial or blood-borne cells. In the present study there was no indication that the presumptive myoblasts were derived from myonuclei, although this has been suggested by others (Reznik 1973; Mastaglia et al. 1975). Recent reports by Snow (1977a, b), and Gutmann et al. (1976) argue against this origin and strongly implicate the muscle satellite cells as the precursor of the presumptive myoblast. At least some of the satellite cells in the ischemic fibers are able to survive in the absence of a blood supply. However, they do not assume the features of presumptive myoblasts until nearby areas become revascularized. An adequate circulation is probably required for delivery of substrates essential for synthetic activities or energy metabolism during the differentiation of satellite cells, but the identity of these factors remains completely undefined. In addition, although satellite cells contain few mitochondria and are thought to be largely dependent on glycolysis (Snow 1973), the delivery of oxygen may also play a role in the differentiation of these cells. Lipton (1977a) has shown that cultured myogenic cells remain undifferentiated in the absence of oxygen.

The sequence of early regenerative events in the grafts was essentially the same as that described by electron microscopy in other muscle grafts (Mastaglia et al. 1975; 
Schiaffino et al. 1975; Lischka et al. 1977; Schmalbruch 1977) and after other types of muscle injury (Allbrook 1962; Schmalbruch 1976; Mäkitie and Teräväinen 1977). Densely packed ribosomes were the predominant feature of presumptive myoblasts and myoblasts, indicating a marked increase in biosynthetic activity over that of the satellite cell. Hitochemical studies of minced muscle (Wagner et al. 1978) show that the pentose shunt is activated during this period, thus providing the necessary ribose.

The biphasic development of myotubes and myoblasts within the original basal laminae tube of the regenerating muscle closely resembles that which occurs during muscle histogenesis (Kelly and Zachs 1969; Ontell and Dunn 1978), except for the presence of the original basal laminae. During normal muscle development a "primary" myotube develops into a myofiber. "Secondary" myoblasts remain associated with the primary myotube. Later these develop into secondary myotubes and separate from the primary fiber. The development of the secondary myoblasts may be responsible for a major portion of the fibers present in normal muscle (Ontell and Dunn 1978; Beerman and Cassens 1977). In grafted muscle the regeneration of multiple myofibers within the original basal lamina could result in hyperplasia. However, counts of fiber number in mature extensor digitorum longus grafts have not suggested any major differences from controls (Carlson 1976), possibly because of the opposing effects of secondary degeneration of some fibers. Also, it is not clear whether or not the satellite cells in the center of the graft survive long enough to allow regeneration of all the original fibers in this region.

An important feature of the fragmenting muscle fiber is the persistence of the original basal lamina, which serves as a scaffold for subsequent regeneration. It remains largely intact but allows the entry into the fibers of phagocytic cells as well as other cells not normally found within the basal lamina, i.e., erythrocytes and fibroblasts. It is not clear how the old basal lamina is removed. Although the fibrocyte has been implicated in the removal of redundant basal lamina (Vracko and Benditt 1972), there was no notable association between fibroblasts and basal lamina in the present study. In general, the basal lamina appeared simply to disintegrate. Debris or fragments of the basal lamina may have been cleared by interstitial macrophages during the early stages of regeneration. Removal of the original basal lamina proceeded more rapidly in the present study than that reported following other types of injury (Vracko and Benditt 1972). Since new basal lamina was added to the myotube at a fairly early stage of development, the presence of basal lamina around muscle fibers appears to be a matter of some priority. Almost nothing is known about the mechanism of its origin on muscle fibers. In vitro studies have shown that the myoblast and myotube are capable of synthesizing at least some of the constituents of extracellular matrix, but fibrocytes may be necessary in the final establishment of a basal lamina (Lipton 1977b).

Circumstantial evidence for regeneration of muscle fibers in the interstitium was noted by Allbrook (1962), but documentation has been lacking. Evidence for the regeneration of fibers outside the original basal lamina was strongly suggested in the present study. Cells which somewhat resembled presumptive myoblasts were occasionally found in the interstitium during the period of fiber destruction. Furthermore, 
myoblasts and presumptive myoblasts were found aligned in chains independent of the original basal lamina. It is possible that satellite cells or some presumptive myoblasts may have migrated away from the original fibers, as has been observed to happen in fiber cultures (Bischoff 1975). The quantitative significance and possible functional role of regeneration outside the confines of the basal lamina remains to be established.

Maturation of the regenerated fibers proceeded as described for other types of muscle grafts (Hikida 1976; Lischka et al. 1977; Schmalbruch 1977) and developing muscle (Goldspink 1972). Maturation was characterized by a migration of most of the nuclei to the periphery. Unlike normal developing muscle, however, some central nuclei persisted in long-term grafts. They were often found in fibers which were otherwise completely normal. Differentiation of fiber types began after the fibers became densely packed with myofibrils. Z-band widths shifted from a predominance of wide bands, characteristic of slowly contracting fibers to a predominance of narrow bands, characteristic of fast-contracting fibers (Gauthier 1971; Eisenberg and Kuda 1977). This study and previous physiological and histochemical studies (Carlson and Gutmann $1975 \mathrm{a}, \mathrm{b}$ ) suggest that stabilization of the properties of regenerated fibers occurs between 30-60 days after grafting. It is assumed that many of the "surviving" denervated fibers became re-innervated. Whereas the fibers that became innervated increased in size, regenerated and surviving fibers which failed to become innervated underwent severe atrophy. Envelopment of some of the fibers by connective tissue may have been a factor in blocking innervation.

In addition to the presence of central nuclei in some muscle fibers and the atrophy of others, the grafts were distinguished from non-grafted muscle by the presence of numerous myo-myous junctions. Myo-myous junctions have been reported in normal avian muscle (Mayr et al. 1967) and in re-innervated limb muscles of the rat (Bormioli and Schiaffino 1977). The myo-myous junctions found between some of the regenerated fibers of mature grafts are probably the equivalent of the acetylcholinesterase-positive structures reported in the regenerating soleus muscle (Schmalbruch 1976). They may be the result of regeneration of more than one fiber within the original basal lamina tube: the ends of some myotubes or myoblasts may have become covered with basal lamina before the cells were able to fuse with other cells located in a more distal region of the fiber. Another possibility is that their formation might be an adaptive response to a quantitatively deficient innervation of muscle grafts. The functional significance of myo-myous junctions remains to be investigated.

\section{ACKNOWLEDGEMENTS}

We thank Mr. John Beckerman for photographic assistance and Maira R. Zuika for typing the manuscript.

\section{REFERENCES}

Allbrook, D. (1962) An electron microscopic study of regenerating skeletal muscle, $J$. Anat.(Lond.), 96: 137-152. 
Beerman, D. H. and R. G. Cassens (1977) Indirect fluorescence of primary and secondary myofibers in developing procine muscle, J. Histochem. Cytochem., 25: 439-442.

Bischoff, R. (1975) Regeneration of single skeletal muscle fibers in vitro, Anat. Rec., 182: 215-236.

Bormioli, S. Pierogon and S. Schiaffino (1977) Myomuscular junctions in reinnervated rat skeletal muscle, J. Anat. (Lond.), 124: 359-370.

Carlson, B. M. (1976) A quantitative study of muscle fiber survival and regeneration in normal, predenervated, and Marcaine-treated free muscle grafts in the rat, Exp. Neurol., 52: 421-432.

Carlson, B. M. (1978) A review of muscle transplantation in mammals, Phvsiol. Bohemoslav., 27: $387-400$.

Carlson, B. M. and E. Gutmann (1975a) Regeneration in free grafts of normal and denervated muscles in the rat - Morphology and histochemistry, Anat. Rec., 183: 47-61.

Carlson, B. M. and E. Gutmann (1975b) Regeneration in grafts of normal and denervated rat muscles - Contractile properties, Pflügers Arch. ges. Physiol, 353: 215-225.

Carlson, B. M. and E. Gutmann (1976) Free grafting of the extensor digitorum longus muscle in the rat after Marcaine pre-treatment, Exp. Neurol., 53: 82-93.

Cullen, M. J. and M. G. Pluskal (1977) Early changes in the ultrastructure of denervated rat skeletal muscle, Exp. Neurol., 56: 115-131.

Eisenberg, B. R. and A. M. Kuda (1977) Retrieval of cryostat sections for comparison of histochemistry and quantitative microscopy in a muscle fiber, J. Histochem. Cytochem., 25: 1169-1177.

Gauthier, G. F. (1971) The structural and cytochemical heterogeneity of mammalian skeletal muscle fibers. In: R. J. Podolsky (Ed.), Contractility of Muscle Cells and Related Processes, Prentice-Hall, Inc., Englewood Cliffs, NJ, pp. 131-150.

Goldspink, G. (1972) Postembryonic growth and differentiation of striated muscle. In: G. H. Bourne (Ed.), The Structure and Function of Muscle, Academic Press, New York, NY, pp. 181-236.

Gutmann, E., V. Mareš and J. Štichová (1976) Fate of ${ }^{3} \mathrm{H}$-thymidine labelled myogenic cells in regeneration of muscle isografts, Cell Tiss. Res., 167: 117-123.

Hikida, R. S. (1976) Regeneration of a tonic avian muscle - Transformation to a twitch morphology, Develop. Biol., 48: 67-79.

Hogan, E. L., D. M. Dawson and F. A. Romanul (1965) Enzymatic changes in denervated muscle, Part 2 (Biochemical studies), Arch. Neurol. (Chic.), 13: 274-282.

Humphrey, C. D. and F. E. Pittmann (1974) A simple methylene blue-azure II-basic fuchsin stain for epoxy-embedded tissue sections, Stain Technol., 49: 9-13.

Jirmanová, I. and S. Thesleff (1972) Ultrastructural study of experimental muscle degeneration and regeneration in the adult rat, $Z$. Zellforsch., 131:77-97.

Kelly, A. M. and S. I. Zacks (1969) The histogenesis of rat intercostal muscle, J. Cell Biol., 42: 135-153.

Kerner, J., A. Sandor and I. Alkonyi (1976) The effect of denervation on carnitine metabolism in rat skeletal muscle, Acta biochim. biophys. Acad. Sci. Hung., 11: 239-243.

Lipton, B. H., (1977a) A fine-structural analysis of normal and modulated cells in myogenic cultures, Develop. Biol., 60: 26-47.

Lipton, B. H. (1977b) Collagen synthesis by normal and bromodeoxyuridine-modulated cells in myogenic culture, Develop. Biol., 61 : 153-165.

Lischka, A., J. Holle and G. Freilinger (1977) Lichtmikroskopische Untersuchungen morphologischen Veränderungen autologer Muskeltransplantation. Acta anat. (Basel), 97: 450-458.

Mäkitie, J. and H. Teräväinen (1977) Ultrastructure of striated muscle of the rat after temporary ischemia, Acta neuropath. (Berl.), 37: 237-245.

Mastaglia, F. L., R. L. Dawkins and J. M. Papadimitriou (1975) Morphological changes in skeletal muscle after transplantation - A light- and electron-microscopic study of the initial phases of degeneration and regeneration, J. neurol. Sci., 25:227-247.

Mayr, R., W. Zenker and H. Gruber (1967) Zwischensehnenfreie Skelettmuskelfaser-Verbindungen, Z. Zellforsch., 79: 319-325.

Neerunjun, J. S. and V. Dubowitz (1974) Muscle transplantation and regeneration in the dystrophic hamster, Part 2 (Histochemical studies), J. neurol. Sci., 23: 521-536.

Ontell, M. and R. F. Dunn (1978) Neonatal muscle growth - A quantitative study, Amer. J. Anat., 152: 539-556.

Price, H. M., E. L. Howes and J. M. Blumberg (1964) Ultrastructural alterations in skeletal muscle fibers injured by cold, Part 2 (Cells of the sarcolemmal tube: observations on "discontinuous" regeneration and fibril formation), Lab. Invest., 30: 1279-1302.

Reznik, M. (1973) Current concepts of skeletal muscle regeneration. In: C. M. Pearson (Ed.), The Striated Muscle, Williams and Wilkins, Baltimore, MD, pp. 185-225. 
Schiaffino, S., M. Sjöström, L. E. Thornell, B. Nyström and L. Hackelius (1975) The process of survival of denervated and freely autotransplanted skeletal muscle, Experientia (Basel), 31: $1328-1330$.

Schmalbruch, H. (1976) The morphology of regeneration of skeletal muscles in the rat, Tissue and Cell, 8: 673-692.

Schmalbruch, H. (1977) Regeneration of soleus muscles of rat autografted in toto as studied by electron microscopy, Cell Tiss. Res., 177:159-180.

Snow, M. H. (1973) Metabolic activity during the degenerative and early regenerative stages of minced skeletal muscle, Anat. Rec., 176: 185-204.

Snow, M. H. (1977a) Myogenic cell formation in regenerating rat skeletal muscle injured by mincing, Part 1 (A fine structural study), Anat. Rec., 188: 181-200.

Snow, M. H. (1977b) Myogenic cell formation in regenerating rat skeletal muscle injured by mincing, Part 2 (An autoradiographic study), Anat. Rec., 188: 201-218.

Thompson, N. (1974) A review of autogeneous skeletal muscle grafts and their clinical applications, N. Amer. Clin. Plastic Surg., 1: 349-403.

Trupin, G. L. (1973) An Ultrastructural Study of the Regeneration of the Minced Gastrocnemius Muscle in the Frog, Ph.D. thesis, University of Michigan.

Vracko, R. and E. P. Benditt (1972) Basal lamina - The scaffold for orderly cell replacement. Observations on regeneration of injured skeletal muscle fibers and capillaries, J. Cell Biol., 55: 406-419.

Wagner, K. R., B. M. Carlson and S. R. Max (1977) Developmental patterns of glycolytic enzymes in regenerating skeletal muscle after autogenous free grafting, J. neurol. Sci., 34: 373-390.

Wagner, K. R., F. C. Kauffman and S. R. Max (1978) The pentose phosphate pathway in regenerating skeletal muscle, Biochem. J., 170: 17-22.

Yarom, R., A. J. Behar, L. Yanko, T. A. Hale and P. D. Peters (1976) Gold tracer studies of muscle regeneration, J. Neuropath. exp. Neurol., 35: 445-457. 